\title{
Why Wait? A Century of Life Before IPO
}

\author{
By Boyan Jovanovic and Peter L. Rousseau*
}

Over the past century the U.S. financial system has grown and become more efficient. Does that mean that ideas are being commercialized faster than before? Apparently not. Using three separate concepts of age, Figure 1 shows that companies that first listed at the close of the 19 th century were as young as the companies that are entering the NYSE, AMEX, and NASDAQ stock exchange today. We argue here that the electricity-era and the informationtechnology-era firms came in younger because the technologies that they brought in were too productive to be kept out very long. The model that we use to explain this resembles Edward C. Prescott and Michael Visscher's (1980) model of the absorption of personnel, and Jovanovic and Yaw Nyarko's (1996) model of learning about a production function.

The figure shows Hodrick-Prescott (HP) filtered average waiting times from founding, from first product or process innovation, and from incorporation to exchange listing. It is based upon individual company histories and our extension of the Center for Research in Security Prices (CRSP) database from its 1925 starting date back through 1885 using newspaper sources. Table 1 shows the coverage by decade.

\section{A Model of the Waiting Time to an Initial Public Offering}

Figure 1 shows that the firm has its first innovation soon after founding, but that it then takes years, even decades, to list on a stock exchange. We shall interpret this delay as a period during which the firm and possibly its lenders learn about what the firm's optimal in-

\footnotetext{
* Jovanovic: Department of Economics, University of Chicago, 1126 East 59th Street, Chicago, IL 60637, and New York University; Rousseau: Department of Economics, Vanderbilt University, Nashville, TN 37235. We thank the NSF for support and Diego Comin and Robert Lucas for comments. Chia-Ying Chang, John Roland, and Quan Yu provided research assistance.
}

vestment is; at the end of this period, an initial public offering (IPO) leads to an influx of capital that enables the firm to implement its idea. Delaying the IPO defers the date when revenues start to come in, but this may still raise the firm's net present value because investment is irreversible and information can help the firm avoid a costly mistake. In this sense the information is an intangible investment that raises the firm's efficiency.

Pharmaceuticals are, perhaps, the only business in which one can so sharply separate the information-gathering stage from the production stage, and even there, the IPO does not coincide exactly with the start of production. Elsewhere, learning and production take place more or less simultaneously; the firm starts small, it learns a little, adds capacity, learns a little more, adds more capacity, changes its product a little, finds new suppliers, invests and hires a few more people, then learns a little more, and the process goes on. The firm defines itself by the investments that it makes and loses flexibility gradually. Here we assume that all investment occurs at the IPO date, and that only then does the firm start to generate revenue.

The production function is

$$
y=A-(\theta-x)^{2} .
$$

Here $y$ is output, $A$ is the known quality of the technology, $\theta$ is an unknown parameter, and $x$ is a decision like the setting of a dial. The firm needs $k$ units of capital to produce, and like $x$, this investment is made at date $T>0$ and is irreversible. We think of $x$ as describing the choice of product, process, inputs, and so on, and we think of $k$ as the cost of creating capacity, of advertising and the like.

Before investing, the firm learns about $\theta$ by observing signals

$$
d s_{t}=\theta d t+\sigma_{\varepsilon} d \varepsilon_{t} \quad \text { for } t \in[0, T]
$$

where $\varepsilon_{t}$ is Brownian motion. The cost of observing the signals is $c$ per unit of time. Firms 


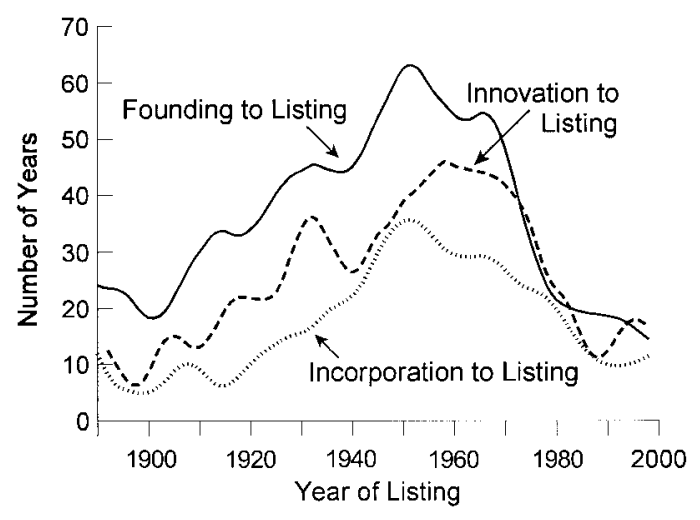

Figure 1. Waiting Times to Exchange Listing

differ in $\theta$, which is distributed normally with mean $\bar{\theta}$ and variance $\sigma_{\theta}^{2}$. A firm does not know its own $\theta$, and the normal distribution is its prior over $\theta$. After $t$ periods of signals generated by (2), the posterior variance $\sigma_{t}^{2} \equiv E_{t}\left(\theta-E_{t}(\theta)\right)^{2}$ is

$$
\sigma_{t}^{2}=\left(\frac{1}{\sigma_{\theta}^{2}}+\frac{t}{\sigma_{\varepsilon}^{2}}\right)^{-1} .
$$

The firm must decide whether to enter and, if it does, when to invest ( $T$ ) and what $x$ to choose. We take these decisions up in reverse order.

Choosing $x$.- Once set, $x$ cannot be changed, and from date $T$ on, the firm's output will be constant. The firm cannot declare bankruptcy no matter how large a mistake $|x-\theta|$ it has made and, so if it is risk-neutral, it will choose $x$ to maximize the expected discounted value of its output, $r^{-1} E_{T}(y)$, for which the optimal decision is

$$
x=E_{T}(\theta) .
$$

Substituting from (4) into (1), the expected lifetime value of the project as of date $t$, net of investment costs, is

$$
\frac{1}{r} E_{t}(y)-k=\frac{1}{r}\left(A-\sigma_{t}^{2}\right)-k
$$

The delay-to-invest serves to accumulate information capital, the value of which is $r^{-1}\left(\sigma_{\theta}^{2}-\right.$ $\left.\sigma_{t}^{2}\right)$.
TABLE 1-Number OF Firms

IN THE Waiting-Time SAMPLE

\begin{tabular}{lrrrr}
\hline \hline & $\begin{array}{c}\text { All } \\
\text { new } \\
\text { listings }\end{array}$ & $\begin{array}{c}\text { Included } \\
\text { incorporations }\end{array}$ & $\begin{array}{c}\text { Included } \\
\text { foundings }\end{array}$ & $\begin{array}{c}\text { Included first } \\
\text { innovations }\end{array}$ \\
Decade & 112 & 52 & 41 & 5 \\
1890's & 112 & 78 & 44 & 10 \\
1900's & 214 & 190 & 97 & 14 \\
1910's & 545 & 492 & 273 & 43 \\
1920's & 231 & 197 & 78 & 26 \\
1930's & 271 & 246 & 97 & 28 \\
1940's & 254 & 241 & 78 & 36 \\
1950's & 2,008 & 964 & 198 & 94 \\
1960's & 4,517 & 1,405 & 262 & 74 \\
1970's & 6,322 & 904 & 790 & 90 \\
1980's & 6,930 & 1,469 & 1,869 & 62 \\
1990's & 6,969 \\
\hline Totals: & 21,516 & 6,238 & 3,827 & 482 \\
\hline
\end{tabular}

Sources: See text (Section III).

Choosing T.-Normalize the founding date to zero. The optimization problem is

$$
\begin{aligned}
v(A) \equiv & \max _{T \geq 0}\left\{e^{-r T}\left[\frac{1}{r} E_{t}(y)-k\right]\right. \\
& \left.-\int_{0}^{T} e^{-r t} c d t\right\} .
\end{aligned}
$$

The optimal $T$ will not depend on the realized signals because the expression for $\sigma_{t}^{2}$ in (3) and, hence, $E_{t}(y)$ depend only on $t$, and not on the signals. At an interior optimum, the firm equates the gains to waiting on the left-hand side of (7) to the sum of the forgone earnings $\left(A-\sigma_{t}^{2}-\right.$ $r k$ ) and observation costs:

$$
-\frac{1}{r}\left(\frac{\partial \sigma_{t}^{2}}{\partial t}\right)=A-\sigma_{t}^{2}-r k+c .
$$

Substitution from (3) into (7) for $\sigma_{t}^{2}$ leads to the optimal waiting time:

(8) $\quad T^{*}=-\frac{\sigma_{\varepsilon}^{2}}{\sigma_{\theta}^{2}}+\frac{2}{r}$

$$
\left(\sqrt{\left[1+4 \frac{(A+c-r k)}{r \sigma_{\varepsilon}^{2}}\right]}-1\right)^{-1}
$$

which decreases with $c$ and $A$ (the direct and indirect cost of sampling) and increases with $\sigma_{\theta}^{2}$ 
(the ignorance that sampling serves to wipe out) and $k$ (the resources committed). It also decreases with $r$ when $r$ is small, and increases with $\sigma_{\varepsilon}^{2}$ when $\sigma_{\varepsilon}^{2}$ is small. Indeed, as $\sigma_{\varepsilon}^{2} \rightarrow 0$, $T^{*} \rightarrow 0$. Finally, for the firm to want to wait in the first place, it is enough that $\sigma_{\theta}^{2}>2(A-r k+$ c).

Entry.-Firms for which $v(A)>0$ enter. The marginal entrant, $A^{*}$, has $v(A)=0$. Assume that

$$
A=z u
$$

where $z$ is an aggregate shock, and $u$ is projectspecific and distributed as $F(u)$. The number of entrants is $1-F\left(A^{*} / z\right)$, so that $z$ raises entry.

Market-book ratios.-If the pre-IPO costs are on the books, the zero-profit condition implies that the market-book ratio for the marginal firm is unity. A higher $z$ raises the number of inframarginal firms and the market-book ratio of the group as a whole.

\section{Explaining the Inverted-U Shape for $T$}

The parameters $z, \sigma_{\theta}^{2}$, and $k$ are about technology, whereas $c$ and $\sigma_{\varepsilon}^{2}$ are also about the financial system. Can we guess how they have evolved? Electricity (1890-1930) and the microcomputer (1971- ) were technologies as widespread in their effects as was steam. One would guess that they gave rise to higher $z$ 's than did the middle of the 20th century, which was the era of the technology-refining incumbent. Since new technology is unfamiliar, $\sigma_{\theta}^{2}$ was probably high in 1890 and 1971 and declined thereafter. Physical capital matters less today than it used to, and $k$ has probably declined. Since $c$ most likely reflects the forgone earnings of the founder and his financiers, it has probably gone up, and $\sigma_{\varepsilon}^{2}$ has probably declined, since it reflects the evaluative expertise of the people managing the project in its infancy.

We shall first consider an explanation based on $z$ alone, then point to its shortcomings, and finally ask whether other parameters may have varied in a way that would remedy things. An explanation based on $z$ is that when great

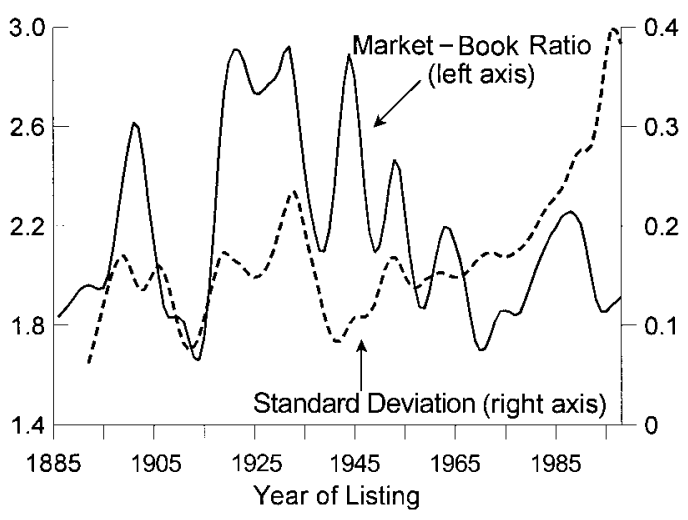

Figure 2. MARKET-BOOK RATIOS FOR 1998 COMPUSTAT FIRMS

projects arrive, firms will be more impatient to implement them, and they will list sooner. Three side implications of such an explanation are, first, that market-book ratios should have been higher in the two eras corresponding to implementation of electricity and microcomputers than in the middle of the century; second, that the smaller $T$ should have led to more mistakes by some firms which, when combined with some lucky guesses by other firms, should have led to a greater dispersion of market-book values for the electricity and the IT cohorts; and, third, that the rate of entry should be higher in the two cohorts. Figure 2 accounts for the ratio of market to book value in 1998 by year of exchange listing for the 6,494 Compustat firms that coincide with our extended CRSP sample. The numerator of the ratio includes equity capital and long-term debt, and the data are adjusted for mergers within the sample. As the model predicts, market-book values are, for the most part, higher for the electricity and IT cohorts. The figure also shows the within-cohort variance of these ratios as a proxy for the variance of $|x-\theta|$ within the cohorts. Except for having different trends, the two series look similar, and the correlation between the detrended series is 0.23 .

The series in Figure 2 are based on the Compustat sample, which does not include all firms listed on the NYSE, AMEX, and NASDAQ exchanges. To consider a wider sample, Figure 3 shows the percentage of 1998 market capitalization in our extended CRSP database attributable 


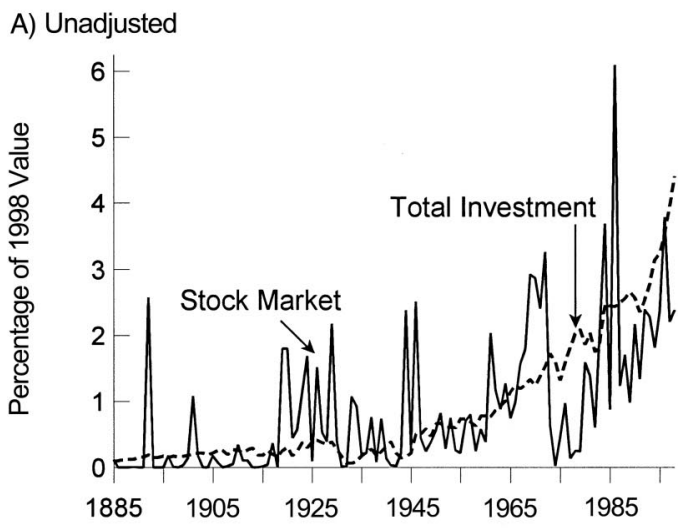

B) Adjusted for Mergers

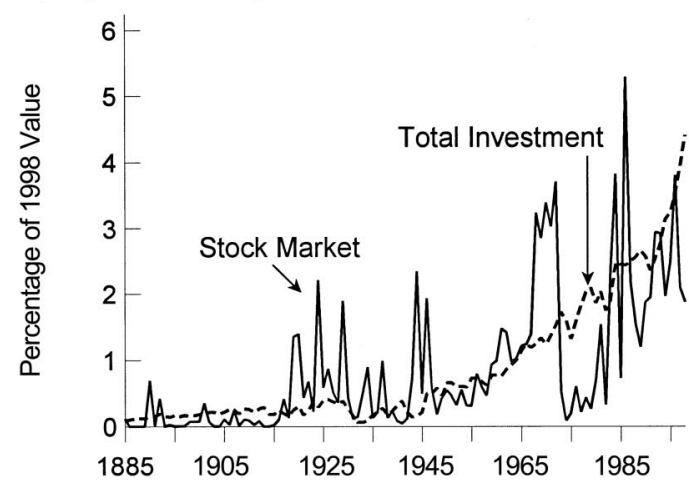

C) Adjusted for Mergers and Net Debt Issuance

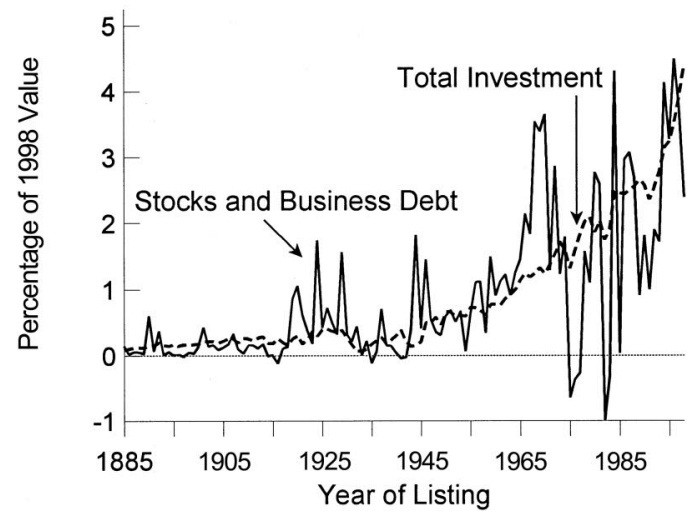

Figure 3. Vintage Composition of Stocks, Business DeBT, AND INVESTMENT IN 1998: (A) UnADJUSTED; (B) Adjusted for Mergers; (C) Adjusted for Mergers and Net Debt Issuance

to each entry year. The dashed line in each panel accounts for total real investment by the vintage of that investment. In panel (A), we use wait times

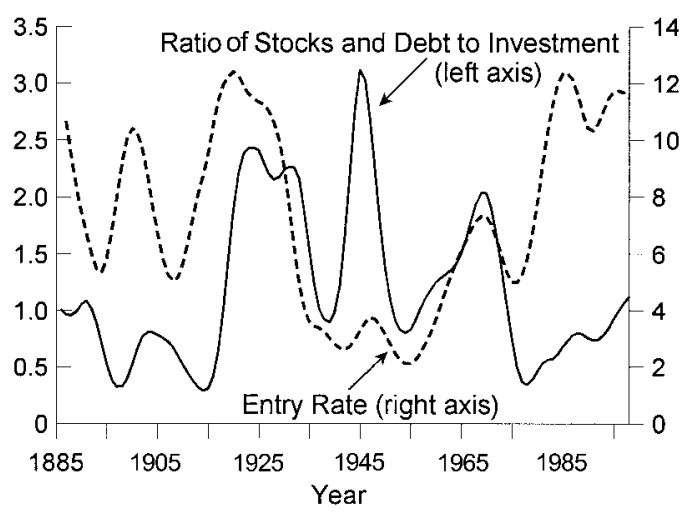

Figure 4. Ratios of Market Value to Investment (Solid Line) ANd Firm Entry Rates (DAshed Line), BY VINTAGE

from incorporation to listing to smooth out spikes in 1962 and 1972 that would coincide with the additions of AMEX and NASDAQ firms to CRSP. Panel (B) adjusts the figure for 5,422 mergers among listed firms, while panel (C) adds real net debt issuance to the solid line. Section III describes these adjustments.

The solid line in Figure 4 is the ratio of surviving entry value to investment. The electricity cohorts appear to have created value in today's market that far exceeds investment at the time of their entry, though this is not the case for the IT cohort. The dashed line, however, which is the percentage of entrants among the firms in each year, shows vigorous entry for both the electricity and IT cohorts, and this confirms the $z$-based explanation.

We will now provide some refinements of this explanation. The market-book values are high during the electrification and IT eras, but the highest values occur in the 1920's and in the mid-late 1980's that is, in the second half of each technological episode. Like $\sigma_{\theta}^{2}, z$ is probably highest at the start of a new technological era, and then, as the best projects are taken up, it probably declines, but so does $\sigma_{\theta}^{2}$. If the decline in the latter dominates the decline in $z$, perhaps one can explain the high performance 20 years or more into the diffusion process. To say more about this, one needs a model in which $z$ and $\sigma_{\theta}^{2}$ are endogenous.

Suppose that, as electricity and IT aged, the best projects were indeed taken up, and that the 
respective $z$ 's fell. This would explain why $T$ rose in the early part of the 20th century, but it would not be consistent with the continuous decline in $T$ after the mid-1970's. To explain this decline one may point to the rapid development of financial institutions and the rise of the venture-capital industry. A rise in $c$ or a fall in $\sigma_{\varepsilon}^{2}$ may explain part of the decline in $T$ since the 1970's, and this line of thinking could be explored further. Finally, the probable decline in $k$ may have contributed to the recent decline in $T$.

\section{Data and Methods}

Figure 1, Table 1.-For 1925-1998, listing years are those for which firms enter CRSP. For 1885-1924, they are years in which prices first appear in the NYSE listings of The Annalist, Bradstreet's, The Commercial and Financial Chronicle, or The New York Times. The combined database defines our sample of 21,516 firms. The 6,238 incorporations in Figure 1 are from Moody's Industrial Manual (1920, 1928, 1955, 1980), Standard and Poor's Stock Market Encyclopedia (1981, 1988, 2000), and various editions of Standard and Poor's Stock Reports. The 3,827 foundings are from Dun and Bradstreet's D\&B Million Dollar Directory (2000), Moody's, Etna M. Kelley (1954), and individual company web sites. The 482 first innovations were obtained by reading company histories in Hoover's Online (2000) and company web sites. We linearly interpolate the series between missing points and HP-filter before plotting.

Figure 2.-Book and market values in 1998 for individual firms are from Compustat. Market value is constructed as book value (item 6) less nominal value of common stock (item 85) plus market value of common stock (the product of items 24 and 25). This implies that debt and preferred stocks enter at their nominal values. Listing years are from our extended CRSP database. We compute the variance of the market-book ratios for any year with two or more surviving entrants. We again interpolate between missing points and HP-filter.

Figure 3.-Private domestic investment is from John Kendrick (1961) for 1885-1953, and from the National Income and Product Accounts thereafter. AMEX firms enter CRSP in 1962, and NASDAQ firms enter in 1972. Since NASDAQ firms traded over-the-counter before 1972 and AMEX's predecessor (the New York Curb Exchange) dates back to at least 1908, we adjust the capitalizations in panel (A) for spikes in 1962 and 1972 by reassigning the capital to an approximation of the "true" entry years. We do this by using Standard and Poor's Stock Report and Stock Market Encyclopedia to obtain incorporation years for 117 of the 274 surviving NASDAQ firms that entered CRSP in 1972 and for 907 of the 5,213 firms that entered NASDAQ thereafter. We then use the sample distribution of differences between incorporation and listing years of the post-1972 entrants to assign the capital of the 1972 entrants into proper "IPO" years; 13.4 percent of the surviving 1998 capital can be attributed to 1972 entrants, but not all entered CRSP via NASDAQ. We therefore assume that the average percentage of 1998 capital attributed to the years 1969-1971 (1.7 percent) entered CRSP in 1972 through NYSE or AMEX, leaving the difference of 11.7 percent to redistribute. We use a similar procedure for the 1962 AMEX entrants.

The merger adjustment in panel (B), as well as that in Figure 2, draws upon several sources. CRSP itself identifies 7,455 firms that exit by merger between 1926 and 1998, but links only 3,488 of them to acquirers. Using the Annual Guide to Stocks: Directory of Obsolete Securities and Predicasts F\&S Index of Corporate Change, however, we found acquirers for 3,646 (91.9 percent) of the unlinked mergers, of which 1,803 were in CRSP. We also examined mergers for 1895-1930 in the manufacturing and mining sectors from work sheets underlying Ralph L. Nelson (1959), and for 1885-1894 from the financial news in weekly issues of The Commercial and Financial Chronicle. We then recursively traced the merger history of every 1998 CRSP firm and its targets, apportioning the 1998 capital of the survivor to its own entry year and those of its merger partners using the share of combined value attributable to each in the year before the merger.

Panel (C) adjusts for the annual change in U.S. business debt, defined as the market value of corporate bonds and commercial and industrial bank loans. For 1945-1998, book values 
are from the Flow of Funds Accounts (2000 [table L.4, lines 5-6]). For 1885-1944, the book value of outstanding corporate bonds is from W. Braddock Hickman (1952), and that of bank loans is from All Bank Statistics, United States and the Historical Statistics of the United States (U.S. Bureau of the Census, 1975). Since the last two sources report 30 June figures, we average across years for consistency with the calendar-year basis of the Flow of Funds Accounts. After ratio-splicing these components into a continuous series, we convert to market values using the average annual yields on Moody's AAA-rated corporate bonds for 19191998 and Hickman's "high grade" bond yields, which line up precisely with Moody's, for 1900-1918. We use yields on "high-grade industrial bonds" from Milton Friedman and Anna J. Schwartz (1982) for 1885-1899. To determine market value, we let $r_{t}$ be the bond interest rate and compute the weighted average

$$
r_{t}^{*}=\frac{1}{\sum_{i=1885}^{t}(1-\delta)^{t-i}} \sum_{i=1885}^{t}(1-\delta)^{t-i} r_{t-i}
$$

We choose $\delta=10$ percent to approximate the growth of new debt plus retirements of old debt, and we multiply the book value of outstanding debt by the ratio $r_{t}^{*} / r_{t}$ to obtain its market value.

Figure 4.- The solid line is the ratio of surviving entry value to investment in panel (C) of Figure 3. The numbers of entrants and listed firms depicted by the dashed line are from our extended CRSP database. We HP-filtered both series before plotting.

\section{REFERENCES}

All-Bank Statistics, United States. Washington, DC: Board of Governors of the Federal Reserve System, 1959.

The Annalist: A Magazine of Finance, Commerce, and Economics. New York: New York Times Co., 1913-1925, various issues.

Annual Guide to Stocks: Directory of Obsolete Securities. Jersey City, NJ: Financial Information, Inc., 2000.

Bradstreet's. New York: Bradstreet Co., 18851925, various issues.
The Commercial and Financial Chronicle. 18851925 , various issues.

Compustat. (Database). New York: Standard and Poor's Corporation, 2000.

CRSP. (Database). Chicago: University of Chicago Center for Research on Securities Prices, 1999.

D\&B Million Dollar Directory. Bethlehem, PA: Dun and Bradstreet, Inc., 2000.

Flow of Funds Accounts, Fourth Quarter 1999. Washington, DC: Board of Governors of the Federal Reserve System, 2000.

Friedman, Milton and Schwartz, Anna J. Monetary trends in the United States and the United Kingdom. Chicago: University of Chicago Press, 1982.

Hickman, W. Braddock. "Trends and Cycles in Corporate Bond Financing." National Bureau of Economic Research (New York, NY) Occasional Paper No. 37, 1952.

Hoover's Online: The Business Network. Austin, TX: Hoover's, Inc., 2000.

Jovanovic, Boyan and Nyarko, Yaw. "Learning by Doing and the Choice of Technology." Econometrica, November 1996, 64(6), pp. 1299-1310.

Kelley, Etna M. The business founding date directory. Scarsdale, NY: Morgan and Morgan, 1954.

Kendrick, John. Productivity trends in the United States. Princeton, NJ: Princeton University Press, 1961.

Moody's Industrial Manual. New York: Moody's Investors Service, 1920, 1928, 1955, 1980.

Nelson, Ralph L. Merger movements in American industry, 1895-1956. Princeton, NJ: Princeton University Press, 1959.

The New York Times. New York: The New York Times Co., 1897-1928, various issues.

Predicasts $\mathrm{F} \& S$ Index of Corporate Change. Cleveland, OH: Predicasts, Inc., 1969-1992.

Prescott, Edward C. and Visscher, Michael. "Organization Capital." Journal of Political Economy, June 1980, 88(3), pp. 446-61.

Stock Market Encyclopedia. New York: Standard and Poor's Corporation, 1981, 1988, 2000.

Stock Reports. New York: Standard and Poor's Corporation, various issues.

U.S. Bureau of the Census, Department of Commerce. Historical statistics of the United States, colonial times to 1970. Washington, DC: U.S. Government Printing Office, 1975. 